\title{
PORTUGUÊS COMO SEGUNDA LÍNGUA E MULTIMODALIDADE ANÁLISE DE UM VÍDEO TUTORIAL PARA ALUNOS SURDOS
}

Eva dos Reis Araújo Barbosa é mestranda em Linguística Aplicada: Linguagem e Tecnologia, pela Faculdade de Letras da UFMG. E-mail: eva.letrasufmg@ hotmail.com

Resumo: Este artigo apresenta a análise de um vídeo tutorial criado para alunos surdos, em duas etapas: análise de trechos do vídeo, por meio da função composicional (KRESS; VAN LEEUWEN, 2006), e avaliação do vídeo completo, a partir da categoria referente ao público a que se destina (GOMES, 2008). Percebemos que o tutorial é um recurso viável para o ensino de português para surdos, em relação ao uso de elementos multimodais e à sua adequação ao público-alvo.

\begin{abstract}
This article presents the analysis of a tutorial video created for deaf students, in two stages: analysis of selected excerpts from the video, through compositional function (KRESS; VAN LEEUWEN, 2006), and evaluation of the video, from the category referring to public it is intended (GOMES, 2008). We noticed that the tutorial is a viable resource for the Portuguese education for the deaf, regarding the use of multimodal elements and their suitability for the target audience.
\end{abstract}

\section{1) INTRODUÇÃO}

$\mathrm{O}$ advento da tecnologia em nossa atual sociedade modificou o modo como os textos são produzidos e consumidos. A cada dia, estamos mais conectados à internet e temos acesso a uma gama de recursos digitais que utilizamos na construção de novos saberes e significados. Alguns exemplos dessas mudanças são apresentados por Kalantzis e Cope (2012):

Cada vez mais, textos contemporâneos envolvem relações complexas entre recursos visuais, o espaço e a palavra escrita: as dezenas de milhares de palavras em um supermercado; o texto escrito nas telas de programas de notícias, esportes ou negócios da televisão; o texto de um caixa eletrônico; sites construídos a partir de ícones visuais e em links ativos de hipertexto; as relações sutis de imagens e textos de revistas em impressão lustrosa, notícias e informações entregues a leitores de e-books; e os textos orais-escritosvisuais híbridos das mensagens instantâneas e dos sites de redes sociais

(KALANTZIS; COPE, 2012, p. 04, tradução nossa).

Essa mudança corrobora com dois fatores importantes, referidos por Kress (2003), que dizem respeito: (1) à mudança do domínio da escrita para o domínio da imagem; e (2) à mudança do domínio do livro para o domínio das telas. Tais fatores fazem com que o letramento não seja mais compreendido de maneira isolada ou apenas centrado em regras gramaticais e na escrita padrão da Língua Portuguesa (LP), mas como uma questão centrada em multiletramentos.

Este conceito refere-se a dois aspectos constitutivos do significado nos dias atuais: (1) o multiculturalismo, que possui relação com a diversidade social e influencia diretamente o modo como interagimos em nossas vidas diárias, tanto local quanto 
globalmente, e como construímos os significados; e (2) a multimodalidade, na qual a escrita possui interface com a modalidade oral, audiovisual, gestual e tátil (KALANTZIS; COPE, 2012). Ambos os aspectos se relacionam ao advento das Novas Tecnologias de Informação e Comunicação (NTICs), conforme ressaltam Kalantzis e Cope (2012):

A abordagem dos Multiletramentos busca explicar o que ainda é importante em abordagens tradicionais de leitura e escrita, e complementar isso com o conhecimento do que é novo e distinto sobre as maneiras pelas quais as pessoas produzem significados no ambiente contemporâneo de comunicação (KALANTZIS; COPE, 2012, p. 01, tradução nossa).

Dessa forma, o mundo atual requer que os alunos sejam cada vez mais capazes de circular e interagir nos diferentes contextos, condições de comunicação e usos de recursos digitais e multimodais, ou seja, "conhecimentos que ultrapassam as fronteiras do impresso" (ZACHARIAS, no prelo, s.p.). Segundo essa autora,

[o] letramento digital, parte desse pluralismo, vai exigir tanto a apropriação das tecnologias, como usar o mouse, o teclado, a barra de rolagem, ligar e desligar os dispositivos, quanto o desenvolvimento de habilidades para produzir associações e compreensões nos espaços multimidiáticos (ZACHARIAS, no prelo, s.p.).

Portanto, é papel do professor desenvolver as capacidades de uso dos mais diversos recursos digitais, por meio do trabalho direcionado aos multiletramentos que incluem a multimodalidade, o letramento digital e o multiculturalismo, para que seus alunos tenham a competência de "entender textos como combinações de possibilidades de significados entre vários modos de linguagem" (HEMAIS, 2010, p. 02). Dessa forma, Nascimento; Bezerra e Heberle (2011) reforçam que "nossa sociedade vive uma nova configuração de práticas textuais que exigem formação atualizada dos professores para

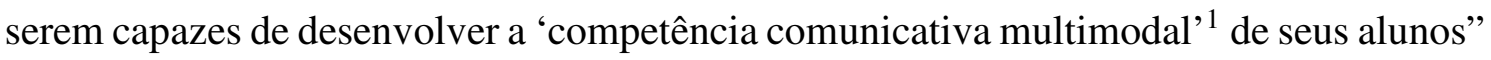
(NASCIMENTO; BEZERRA; HEBERLE, 2011, p. 548-549).

Frente às mudanças ocorridas no modo de aprender e no modo de ensinar a partir dos recursos digitais, dos diferentes contextos sociais e da multimodalidade, Kalantzis e Cope (2012) apresentam alguns deveres que devem fazer parte da prática docente, uma vez que, "se queremos ter 'novos alunos' precisamos de nada menos do que 'novos professores"” (KALANTZIS; COPE, 2012, p. 11, tradução nossa). Esses deveres são:

- engajar os estudantes a serem construtores ativos do seu próprio conhecimento;

- desenvolver ambientes de aprendizagem ao invés de apenas passar o conhecimento;

- providenciar oportunidades de utilização dos novos recursos digitais;

\footnotetext{
${ }^{1}$ Segundo Heberle (2010), a competência comunicativa multimodal diz respeito ao conhecimento e ao uso da linguagem audiovisual, gestual e espacial de comunicação, incluindo a linguagem mediada pela comunicação via computador.
} 
- deixar que os alunos tenham mais responsabilidade sobre sua aprendizagem;

- ser colaborativo com outros professores;

- criar experiências de aprendizagem apropriadas para cada tipo de estudante.

Um público específico que se beneficia muito com o uso das NTICs diz respeito aos alunos surdos, que possuem a Língua Brasileira de Sinais (Libras) como primeira língua (L1), e a LP escrita como segunda língua (L2). Nogueira (2014) cita que algumas pesquisas têm sugerido o uso das NTICs "como recurso viável para a participação social e o processo de aprendizagem de surdos" (NOGUEIRA, 2014, p. 21). Dentre os recursos digitais disponíveis para o trabalho com o aluno surdo, encontra-se o vídeo tutorial. Segundo Dal Forno (2013, p. 2583):

\begin{abstract}
Os recursos educacionais, especialmente vídeo, imagem e áudio, se somam nos vídeos tutoriais e explicitam a sua relevância tendo em vista a necessidade de se apresentar materiais em diferentes formatos aos professores para que estes, por sua vez, também busquem inserir em seus planejamentos novos e diversificados recursos e, com isso, favoreçam a construção do conhecimento de todos os seus estudantes (DAL FORNO, 2013, p. 2583).
\end{abstract}

A partir do exposto, este artigo tem como principal objetivo apresentar a análise de um vídeo tutorial produzido para alunos surdos e ouvintes, utilizando: (1) os critérios propostos por Kress e van Leeuwen (2006) na Gramática do Design Visual, para a leitura de imagens; e (2) a categoria referente ao público a que se destina, proposta por Gomes (2008). Os critérios e a categoria de análise utilizados são apresentados em uma seção específica para esse fim.

Além disso, buscamos responder às seguintes questões: (1) como o vídeo tutorial, por meio de seus recursos multimodais, pode contribuir ao ensino/aprendizagem do Português como Segunda Língua (PL2) para alunos surdos?; e (2) por que o vídeo tutorial produzido é adequado ao público a que se destina, ou seja, aos alunos surdos?

Nossa hipótese é a de que o vídeo tutorial se apresenta como um recurso digital que contribui para o processo de ensino/aprendizagem de PL2 para surdos, através da exploração de vários modos de linguagem para a construção do significado, além de ser adequado a esse público de alunos, devido aos recursos visuais que o compõe. Segundo Freire (2003), a surdez é considerada como uma "experiência visual", dessa forma, o uso da informação verbal interligada à imagem, se configura como um facilitador para o ensino/aprendizagem desse público de alunos.

\title{
2) REFERENCIAL TEÓRICO
}

Esta seção apresenta, de maneira sucinta, a base teórica da pesquisa realizada. Primeiramente, tratamos dos conceitos de multiletramentos, multimodalidade $e$ letramento digital, considerando sua importância para os alunos em nosso atual contexto social. Depois, citamos brevemente duas perspectivas pelas quais as pessoas surdas são 
vistas em nossa sociedade e abordamos os principais benefícios do uso das NTICs no ensino de PL2 para surdos. Por fim, discutimos a respeito da produção de vídeos tutoriais como recursos pedagógicos que podem ser utilizados pelos professores no ensino de PL2 para alunos surdos.

\section{1) Multiletramentos, Multimodalidade e Letramento Digital}

O termo multiletramentos foi cunhado pelo New London Group, composto por pesquisadores que se reuniram para discutir a respeito de um possível futuro para a educação por meio de uma pedagogia dos multiletramentos, no ano de 1996. Tal pedagogia foi fundamentada em interpretações dos estudiosos, relacionadas às mudanças ocorridas no mundo contemporâneo em relação ao trabalho, à educação formal, à cidadania e à vida pessoal. Nessa perspectiva, "todas as formas de representação, incluindo a língua [escrita e oral], são consideradas como processos dinâmicos de transformação" (KALANTZIS; COPE, 2013, p. 02, tradução nossa). Dessa forma, a pedagogia dos multiletramentos defende que a escola não deve privilegiar apenas o cânone literário e a norma padrão da língua imposta pela gramática tradicional, mas deve levar em consideração todos os modos de produção de sentidos, incluindo os imagéticos, os sonoros e os gestuais, por exemplo.

Segundo Nascimento; Bezerra e Heberle (2011), pesquisas na área dos multiletramentos demonstram que é necessário "considerar o modo como outros recursos semióticos, além da linguagem verbal, se inter-relacionam em textos", isso se deve ao fato de que "não existem textos monomodais ou monosemióticos, já que, mesmo em textos predominantemente verbais, utilizamos recursos visuais, tais como tipografia e formatação" (NASCIMENTO; BEZERRA; HEBERLE, 2011, p. 529-530). Ainda segundo os autores:

Percebe-se, assim, que não podemos lidar com a escrita e com a leitura da mesma forma de anos atrás, visto que a realidade vivenciada por nossos alunos e por nós exige ações imediatas no sentido de compreender como texto verbal e imagens realizam significados culturais (NASCIMENTO; BEZERRA; HEBERLE, 2011, p. 532).

Em relação à leitura, Coscarelli e Novais (2010), afirmam que se trata de uma operação muito importante no mundo digital e precisa ser considerada como um processo que une vários tipos de linguagens. As autoras também afirmam que, embora não possamos considerar o texto eletrônico como uma revolução, em relação ao processo de compreensão da leitura na página impressa, ele possui algumas inovações em sua interface, ou seja, "elementos gráficos e de navegação que são diferentes daqueles usados no impresso" (COSACARELLI; NOVAIS, 2010, p. 35). Dessa forma, é importante levar em consideração não apenas os elementos verbais desses textos, mas todo o conjunto de linguagens envolvidas em sua produção.

Portanto, não é mais suficiente que a escola desenvolva uma pedagogia voltada apenas ao letramento das mídias impressas, sendo imprescindível o desenvolvimento do letramento multimodal dos alunos, incluindo o digital e sua composição na tela do 
computador. Esse processo é facilitado através do trabalho com a multimodalidade que é definida por Kress e van Leeuwen (2001) como:

[...] o uso de vários modos semióticos no design de um produto ou evento semiótico, em conjunto com a maneira particular na qual estes modos são combinados - eles podem, por exemplo, reforçar um ao outro ("dizer a mesma coisa de maneiras diferentes"), desempenhar papéis complementares, [...] ou serem ordenados hierarquicamente (KRESS; VAN LEEUWEN, 2001, p. 20, tradução nossa).

Assim, "o aluno precisa entender que existem [...] [diferentes linguagens] e que elas são, ao mesmo tempo, independentes e interativas, na criação de significados" (UNSWORTH, 2001 apud HEMAIS, 2010, p. 1).

Entretanto, Zacharias (no prelo) aponta três grandes desafios enfrentados quando se trata de desenvolver o letramento digital: (1) a leitura como objeto de ensino não pode ser simplificada, ou seja, devem ser consideradas as habilidades cognitivas e seus propósitos comunicativos enquanto prática social; (2) a inclusão de tecnologias deve levar em consideração os sentidos a elas atribuídos no contexto social de maneira não artificial; e (3) os professores devem refletir sobre sua prática e estar em constante formação, a fim de promoverem mudanças que são necessárias para o processo de ensino/aprendizagem de seus alunos.

Essas dificuldades ganham dimensões mais acentuadas quando o professor se depara com um aluno que possui algumas especificidades educacionais, como é o caso dos alunos surdos. Muitas vezes, o aluno surdo se encontra em processo de inclusão e é o único surdo em uma sala de aula composta por ouvintes, contando apenas com o auxílio do profissional intérprete de Libras. Dessa forma, o professor precisa buscar

Segundo Lacerda (2000 apud LACERDA; LODI, 2009), na proposta de inclusão escolar, o professor atua como mediador e incentivador da construção do conhecimento, porém, a interação em sala de aula não acontece de maneira eficaz, uma vez que o surdo, em geral, não compartilha da mesma língua que seus colegas e professores, tendo o contato somente com o intérprete de Libras/Português.

recursos que auxiliem o seu trabalho e que contribuam para o seu aprendizado. Nesse contexto, as NTICs atuam como uma ferramenta importante, conforme pode ser visto na próxima seção.

\section{2) Uso de NTICs no ensino de PL2 para alunos surdos}

Segundo Gesser (2009), geralmente, a pessoa surda é vista a partir de uma perspectiva "exclusivamente fisiológica (déficit de audição), dentro de um discurso de normalização, cujas nomeações, como todas as outras, imprimem valores e convenções na forma como o outro é significado e representado" (GESSER, 2009, p. 46). Assim:

[...] o surdo é visto como portador de uma deficiência física, que precisa de recursos ou intervenções cirúrgicas para se tornar "normal" e fazer parte do grupo majoritário na sociedade em que vive. Ver a surdez como um problema está diretamente relacionado à visão patológica (GESSER, 2009, p. 63). 
Neste artigo, porém, adotamos uma visão sócio-antropológica da surdez, na qual o surdo é considerado como um indivíduo que faz "parte de uma minoria linguísticocultural e utiliza a língua de sinais, independente de seu grau de surdez" (SKLIAR, 1997, 1998, 1999 apud SILVA, 2010, p. 12). Dessa forma, os surdos são as pessoas que apreendem o mundo por meio de suas experiências visuais e possuem pleno direito de apropriarem-se da Libras como L1 e da LP como L2 (MEC, 2004).

Pesquisas na área da Educação de Surdos vêm demonstrando que a Educação

Bilíngue é a proposta mais adequada para o ensino desses alunos, uma vez que "considera a língua de sinais como língua natural e parte desse pressuposto para o ensino da língua escrita" (QUADROS, 1997, p. 27). Assim, a LP deve ser ensinada por meio da leitura e da escrita e esse ensino deve ser significativo para a vida do aluno surdo, já que, apesar de não se tratar de sua L1, o português é essencial para sua participação como cidadão na sociedade em que vive. Segundo Nogueira (2014):

Grande parte destas pesquisas também aponta o aspecto visual como bastante relevante para o processo de aprendizagem do surdo, havendo, portanto, de um modo geral, a preocupação de retirar esse aluno do lugar de margem que lhe restou em seu processo de educação (NOGUEIRA, 2014, p. 21).

Nesse contexto, as tecnologias se apresentam como recursos importantes no processo de ensino/aprendizagem dos alunos surdos. Segundo Ribeiro (2012), a tecnologia integra o acervo cultural da comunidade surda, "desde os antigos aparelhos TDD até as campainhas que acionam luzes, os despertadores vibratórios e os mais recentes softwares de tradução Libras/português (e vice-versa)" (RIBEIRO, 2012, p. 96), que auxiliam na melhoria de sua qualidade de vida. Além disso, de acordo com a autora, "a informática tem sido considerada por muitos professores como uma das áreas de melhor desempenho escolar dos surdos" (RIBEIRO, 2012, p. 96).

Em relação ao ensino de PL2, Ribeiro (2012) afirma que as interfaces tecnológicas maximizam o tempo de exposição dos alunos surdos ao português, além disso, essas ferramentas aproximam os sujeitos surdos da cultura letrada e possibilitam o exercício efetivo de seu letramento, já que eles têm a possibilidade de utilizar a LP escrita em contextos reais de uso. A autora também acredita que o ensino de PL2 para surdos pode extrapolar o domínio físico da sala de aula e que, para isso, o "professor regente da sala inclusiva ou da sala de recursos deverá lançar mão de estratégias outras para atingir seus objetivos (ensinar LP como L2)" (RIBEIRO, 2012, p. 103).

Nogueira (2014) também apresenta alguns benefícios do uso das NTICs no ensino de PL2 para surdos, tais como: uma maior possibilidade de comunicação (através da escrita da LP ou da Libras); um maior acesso à informação (através do auxílio dos recursos visuais); o uso de diferentes linguagens que permitem outras formas de comunicação, "não apenas pela escrita, mas pela sua interação com a imagem, o vídeo, a cor, o som, entre outras semioses, construindo novos significados" (NOGUEIRA, 2014, p. 23). 
Acreditamos que o vídeo tutorial é um dos recursos digitais que podem ser utilizados para facilitar o trabalho do professor de PL2 para surdos e o processo de ensino/aprendizagem desses alunos, uma vez que integra diversas linguagens na produção de significados, tais como: a linguagem verbal, a imagem estática e em movimento como em vídeos, os gestos nos sinais da Libras, as cores, entre outros. Tratamos melhor desse assunto na seção, a seguir.

\section{3) Os vídeos tutoriais como recursos pedagógicos no ensino de PL2 para alunos surdos}

Segundo Dal Forno (2013), a maioria dos professores está ciente de que os recursos educacionais fomentam a aprendizagem dos alunos, contudo, a autora enfatiza que, geralmente, "a escolha do recurso a ser usado é feita em função daqueles que já são mais conhecidos e comumente usados pelos professores, como lousa e giz, retroprojetor e, mais atualmente, o data-show". Porém, "percebe-se cada vez mais a necessidade de produção de recursos educacionais que possam ser acessados por usuários em qualquer parte do mundo, via internet" (DAL FORNO, 2013, p. 2578).

Dessa forma, os vídeos tutoriais se configuram como recursos educacionais importantes tanto para a aprendizagem dos alunos, quanto para o trabalho do professor. Em relação aos alunos, através do vídeo tutorial, eles podem visualizar todo seu conteúdo em etapas, ou seja, podem interromper a exibição a qualquer momento para averiguar alguma dúvida que tenha surgido. Além disso, os alunos podem assisti-lo quantas vezes quiserem, a fim de compreenderem melhor o que foi exposto. Já em relação ao professor o vídeo tutorial é uma ferramenta essencial para a orientação de seus alunos e para a complementação de sua explicação dada no momento da aula, facilitando a compreensão do conteúdo, através do uso de imagens, animações, legendas, etc. (DAL FORNO, 2013). Santos e Kloss (2010) definem o vídeo como:

\footnotetext{
uma gravação de imagens em movimento, uma animação composta por fotos que resultam em uma imagem animada, e principalmente as diversas formas para se gravar imagens em fitas (analógicas ou digitais) [...]. Ele é uma tecnologia relativamente barata, de fácil acesso e de ampla utilização, facilitando seu uso nas escolas, no uso pedagógico (SANTOS; KLOSS, 2010, p. 05).
}

Ainda segundo os autores, o vídeo serve para "introduzir um novo assunto, para despertar a curiosidade, a motivação para novos temas, facilitar o desejo de pesquisa nos alunos e do conteúdo didático" (SANTOS; KLOSS, 2010, p. 06). O vídeo, além de surpreender os alunos, tem o potencial de atender a "todas as demandas, para todos os gostos e idades, procurando sempre auxiliar para melhor satisfazer as necessidades de quem precisa e busca por esta tecnologia que se destaca a cada dia" (SANTOS; KLOSS, 2010, p. 05).

A respeito da capacidade de atender às necessidades dos alunos, Dal Forno (2013) aponta que o professor deve levar em consideração o contexto de cada estudante para 
direcionar a ele as demandas específicas, de modo a facilitar a construção de seu conhecimento. Para tanto, a autora afirma que:

\footnotetext{
É de extrema importância que os professores aprendam a criar suas próprias ferramentas, tendo em conta, entre outros aspectos, a especificidade de cada turma, as características individuais de aprendizagem dos estudantes, e, alguma eventual necessidade educacional especial (DAL FORNO, 2013, p. 2583).
}

Portanto, podemos perceber que os vídeos tutoriais são recursos pedagógicos que podem auxiliar no processo de ensino/aprendizagem dos alunos surdos, uma vez que os professores podem se valer dos recursos visuais (legenda, imagem, sinais, cores, etc.) para a explicação dos conteúdos dados em sala de aula (NOGUEIRA, 2014). Esses vídeos facilitam a compreensão da LP pelos surdos, já que, no contexto de ensino presencial e na sala de aula de inclusão, "aliar interfaces tecnológicas ao ensino de línguas para surdos pode resolver uma parte dos inúmeros problemas surgidos pela inclusão de alunos surdos" (RIBEIRO, 2012, p. 98), ou seja, alunos que estão em um ambiente de educação linguística, voltado para alunos ouvintes (usuários nativos da língua portuguesa).

\section{3) METODOLOGIA}

O objetivo principal deste artigo é apresentar a análise de um vídeo tutorial produzido para alunos surdos e ouvintes, utilizando: (1) os critérios da Gramática do Design Visual, propostos por Kress e van Leeuwen (2006), para a análise de imagens; e (2) a categoria referente ao público a que se destina, proposta por Gomes (2008). Dessa forma, a pesquisa realizada se configura como documental. Segundo Laville e Dione (1999), um documento pode ser algo mais do que um pergaminho poeirento, "o termo designa toda fonte de informações já existente. Pensa-se, é claro, nos documentos impressos, mas também em tudo que se pode extrair dos recursos audiovisuais" (LAVILLE; DIONE, 1999, p. 166).

Ainda segundo os autores, "os documentos sonoros e visuais são também portadores de informações úteis, ainda que ocupem menos espaço que os anteriores no campo da pesquisa" e, dentre os documentos existentes, "colocam-se os discos e fitas magnéticas, as fotos, pinturas, desenhos, os filmes e vídeos, etc." (LAVILLE; DIONNE, 1999, p. 167).

Para descrever a metodologia utilizada, esta seção apresenta, primeiramente, o corpus analisado e seu contexto de produção e, em seguida, os critérios de análise que foram utilizados.

\section{1) Contexto de produção do corpus analisado}

O vídeo Tutorial do bom navegador (Acessível para alunos surdos e ouvintes) foi um trabalho produzido para uma disciplina de Mestrado em Estudos Linguísticos, que 
tratava de estratégias de leitura online, seguindo algumas etapas apresentadas nessa seção. Primeiramente, foi criada uma questão na qual os alunos deveriam realizar uma pesquisa online sobre os principais pontos turísticos da cidade de Belo Horizonte, para a criação do gênero textual Guia Turístico. Após a criação da atividade de pesquisa online, foram criadas algumas sugestões para que os alunos realizassem uma boa navegação, tendo em vista a diversidade de alunos presentes em uma sala de aula de inclusão: (1) alunos ouvintes; (2) alunos surdos que sabem Libras; e (3) alunos surdos que não sabem a Libras.

Os objetivos desse vídeo tutorial eram: (1) criar oportunidades para que todos os alunos, independente de suas especificidades educacionais, pudessem realizar uma boa navegação no processo de desenvolvimento de sua pesquisa; e (2) apoiar o trabalho do professor de português que possui alunos surdos e ouvintes em sala de aula. Esses objetivos serviram como roteiro para a produção do vídeo tutorial. O processo de gravação seguiu os seguintes passos:

1. Tradução Português/Libras do conteúdo do roteiro de gravação, através de glosas $^{2}$;

2. Gravação do áudio das glosas em português, fazendo o uso do celular;

3. Gravação em vídeo da interpretação em Libras com uma câmera digital;

4. Edição dos vídeos gravados no programa Movie Maker ${ }^{3}$;

5. Gravação das telas do computador e de seus respectivos áudios referentes aos percursos percorridos durante a navegação da pesquisa (tutorial em si), utilizando o programa Camtasia ${ }^{4}$

6. Busca e seleção de imagens relacionadas ao conteúdo do vídeo tutorial no Google Imagens;

7. Junção da gravação das telas, dos áudios e das imagens com o programa Movie Maker;

8. Inclusão do vídeo de interpretação em Libras no vídeo tutorial, utilizando o programa Camtasia;

9. Legendagem do vídeo, levando em consideração a interpretação em Libras, pelo uso do programa Movie Maker;

\footnotetext{
${ }^{2}$ O termo glosa foi importado para a Libras a partir da Língua de Sinais Americana (ASL), é se trata de um sistema de transcrição no qual "uma palavra em inglês (ou outra língua oral), grafada em maiúsculo, é usada para representar o sinal manual com o mesmo sentido. Algumas marcações não-manuais são acrescentadas por códigos sobrescritos, e alguns usos do espaço de sinalização são representados por letras ou números subscritos" (MCCLEARY; VIOTTI, 2005, p. 2-3).
}

${ }^{3}$ Segundo os criadores do programa, “o Windows Movie Maker é um recurso do Windows Vista que permite criar filmes domésticos e apresentações de slide no computador, completar com títulos de aparência profissional, transições, efeitos, música e até mesmo narração". Disponível em: <<http://windows.microsoft.com/pt-br/windows-vista/getting-started-with-windows-movie-maker $>>$. Acesso em: 15 jun. 2015.

\footnotetext{
${ }^{4}$ Segundo o site Techtudo, "o Camtasia Studio é uma ferramenta de captura e gravação de tela para Windows e Mac. O programa possui diversas opções para edição e montagem de vídeos. Ele é ideal para a criação de tutoriais em vídeo e apresentações de slides". Disponível em:

<<http://www.techtudo.com.br/tudo-sobre/camtasia-studio.html >>. Acesso em: 15 jun. 2015.
} 
10. Postagem do vídeo finalizado na rede social Youtube.

As ações, descritas nos passos acima, demonstram que o vídeo tutorial analisado é composto por diversos modos de linguagem: a imagem estática e em movimento pelo vídeo, o sonoro pelo áudio, o verbal, o espacial e o gestual. Conforme pode ser visto na Figura 01, a seguir:

Figura 01 - Diferentes modos de linguagem utilizados no vídeo tutorial

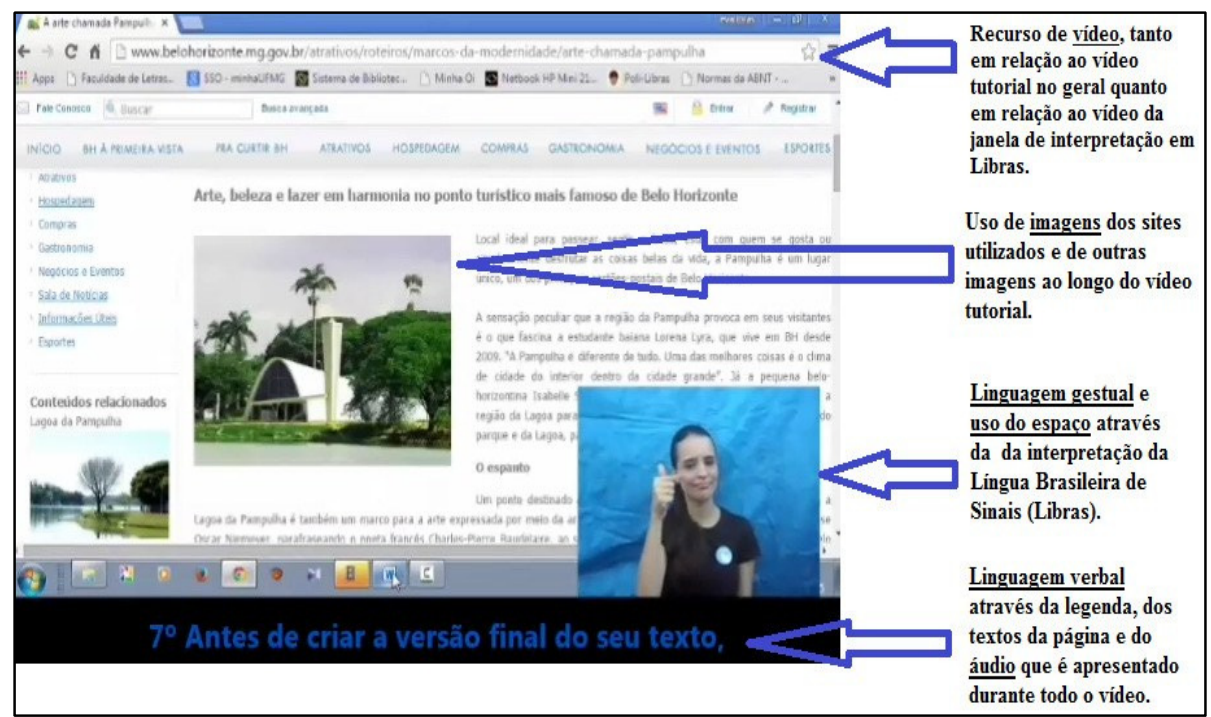

Fonte: Arquivos da pesquisa.

Para a análise desse vídeo tutorial, foram selecionados alguns trechos, registrados em prints da tela do computador, conforme exemplo apresentado acima, para a composição do corpus dessa pesquisa. Foram, então, aplicadas as categorias de análise visual propostas por Kress e van Leeuwen (2006). Além disso, analisamos o vídeo tutorial completo, tendo por suporte a proposta de Gomes (2008). Esses critérios são apresentados a seguir.

\section{2) Critérios utilizados na análise dos dados}

Segundo Rose (2007), "os meios audiovisuais são um amálgama complexo de sentidos, imagens, técnicas, composição de cenas, sequência de cenas e muito mais" (ROSE, 2007, p. 344). Portanto, segundo a autora, é imprescindível levar em consideração essa complexidade durante a análise de seu conteúdo e de sua estrutura. Ademais, a autora afirma que, durante a escolha dos trechos que serão analisados pelo pesquisador, "o que 
é deixado de fora é tão importante quanto o que está presente” (ROSE, 2007, p. 343). Dessa forma, o pesquisador precisa ser o mais explícito possível em relação aos recursos que serão empregados em sua análise, uma vez que "as representações da mídia são mais que discursos", ou seja, são um "complexo de texto, escrito ou falado, imagens visuais, e as várias técnicas para modular e sequenciar a fala, as fotografias e a localização de ambas" (ROSE, 2007, p. 345).

Em nossa pesquisa, os trechos selecionados do vídeo tutorial serão tratados como imagens estáticas e analisados com base nos critérios propostos por Kress e van Leeuwen na Gramática do Design Visual (2006). Esses pesquisadores propõem que as imagens expressam seus significados através de três diferentes funções: (1) a função representacional, responsável pela estrutura visual das imagens, por meio de representações narrativas e representações conceituais; (2) a função interacional, responsável pela relação entre os recursos visuais que compõem a imagem, através do contato, da distância social, da atitude e do poder que dela emana; e (3) a função composicional, responsável pela organização dos elementos representados na imagem.

A análise apresentada neste artigo leva em consideração apenas a função composicional que inclui os seguintes recursos:

1. Enquadramento: indica a presença ou a ausência de recursos de enquadramento (como, por exemplo, linhas de divisão e quadros) que desconectam ou conectam elementos da imagem, fazendo com que eles façam parte juntos ou não da produção de algum sentido.

2. Saliência: é relacionada ao fato de que os elementos são criados com o intuito de atrair a atenção do espectador em diferentes graus, que são percebidos por fatores tais como: a colocação em primeiro ou segundo plano, o tamanho relativo, o contraste das cores, as diferenças de nitidez, etc.

3. Valor de informação: diz respeito à colocação de elementos em determinados locais da página, que os dotam com valores informativos específicos associados às diversas "zonas" da imagem: esquerda e direita (dado/novo), superior e inferior (real/ideal), centro e margem (central/marginal).

Já em relação à análise do vídeo tutorial completo, utilizamos uma das cinco categorias elencadas por Gomes (2008) que podem ser usadas para nortear o professor na produção e na utilização de vídeos como materiais didáticos. São estas as categorias:

(1) Conteúdos; (2) Aspectos técnico-estéticos; (3) Proposta Pedagógica; (4) Material de Acompanhamento; e (5) Público a que se destina. Neste artigo, vamos fazer uso somente da última categoria que contém os seguintes itens:

- Público é claramente definido e identificável.

- Previsão de conhecimento prévio do público-alvo é atendida.

- Proposta pedagógica adequada ao público-alvo. 
- Linguagem adequada ao público-alvo.

- Formato adequado ao público-alvo (GOMES, 2008, p. 489).

Porém, Gomes (2008) enfatiza que, embora tenha elencado cinco categorias que parecem fundamentais para uma boa análise, o professor deve considerar aqueles que estão de acordo com seu contexto de trabalho e com as especificidades de seus alunos.

Esse autor destaca ainda que há uma carência de pesquisas que indiquem critérios para a análise e a avaliação da qualidade dos produtos audioviosuais.

A partir de uma apresentação breve dos critérios de análise utilizados nesta pesquisa, enfocamos, a seguir, a análise do vídeo tutorial e os resultados encontrados.

\section{4) ANÁLISE DOS DADOS E RESULTADOS}

Esta seção apresenta a análise realizada e os resultados encontrados. Primeiramente, tratamos dos aspectos composicionais dos trechos escolhidos do vídeo tutorial, fazendo uso dos recursos propostos por Kress e van Leeuwen (2006). Depois, analisamos o vídeo tutorial completo, com base na categoria referente ao público a que se destina, proposta por Gomes (2008).

\section{1) Função Composicional}

$\mathrm{O}$ primeiro aspecto analisado em relação à função composicional dos trechos selecionados do vídeo tutorial, diz respeito ao enquadramento, pelo qual, segundo Kress e van Leeuwen (2006), é possível perceber se os elementos estão interligados, representando uma unidade, ou separados, indicando uma individualidade. Podemos perceber o uso desse recurso já na abertura do vídeo, conforme pode ser visto na Figura 02, abaixo:

Figura 02 - Enquadramento no vídeo tutorial

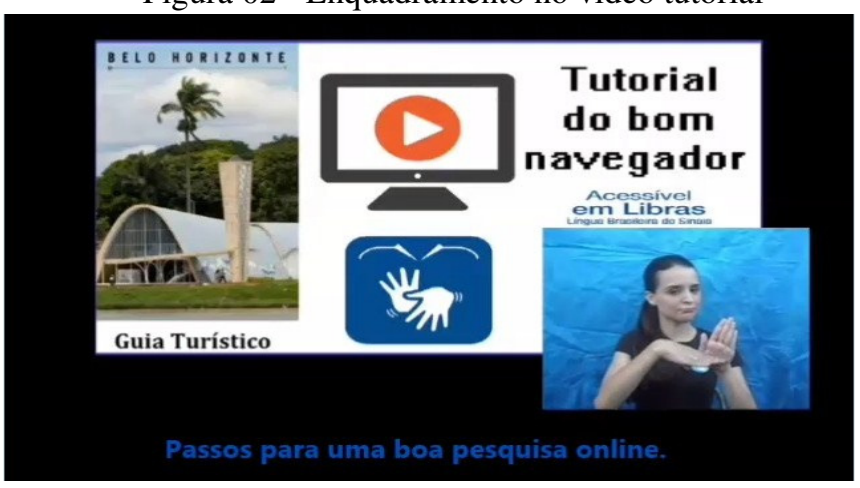

Fonte: Arquivos da pesquisa.

Nessa figura, retirada do vídeo tutorial, temos quatro diferentes tipos de enquadramento. O primeiro se dá pelas linhas divisórias do Guia Turístico de Belo Horizonte, o qual é tema da atividade proposta aos alunos no vídeo tutorial. O segundo enquadramento acontece pela ausência de linhas divisórias entre as imagens da tela de um 
computador, do "Símbolo Acessível em Libras 5 " e do título do vídeo tutorial, demonstrando que tais elementos possuem uma relação entre si, já que todos estão representados em um mesmo quadro de fundo branco. Já o terceiro enquadramento aparece na janela de interpretação do conteúdo do vídeo em Libras, em fundo azul, na qual há a presença da intérprete. Há ainda um quarto tipo de enquadramento, que engloba o vídeo tutorial como um todo, onde a legenda aparece na base sem linhas divisórias, o que demonstra que ela está relacionada com todo o conteúdo do vídeo, principalmente em relação à interpretação em Libras, visto que a cor da letra é a mesma que aparece no fundo da janela da intérprete.

Esse recurso utilizado no vídeo tutorial é importante para que haja uma melhor compreensão de seu conteúdo pelo aluno surdo, uma vez que auxilia na delimitação do tema do vídeo e no entendimento da relação entre os elementos presentes na tela. Dessa forma, no caso dos alunos surdos, as imagens utilizadas, bem como a interpretação em Libras e a legenda, auxiliam na compreensão da linguagem verbal utilizada, sendo o enquadramento um elemento visual importante nesse processo.

$\mathrm{O}$ segundo aspecto analisado em relação à função composicional diz respeito à saliência, a qual é resultado de uma interação complexa entre vários fatores, tais como: tamanho, nitidez, foco, contraste de cor, perspectiva e, também, fatores culturais. Esse recurso pode ser encontrado em várias partes do vídeo tutorial, sendo uma delas apresentada na Figura 03, abaixo:

Figura 03 - Saliência da imagem no vídeo tutorial

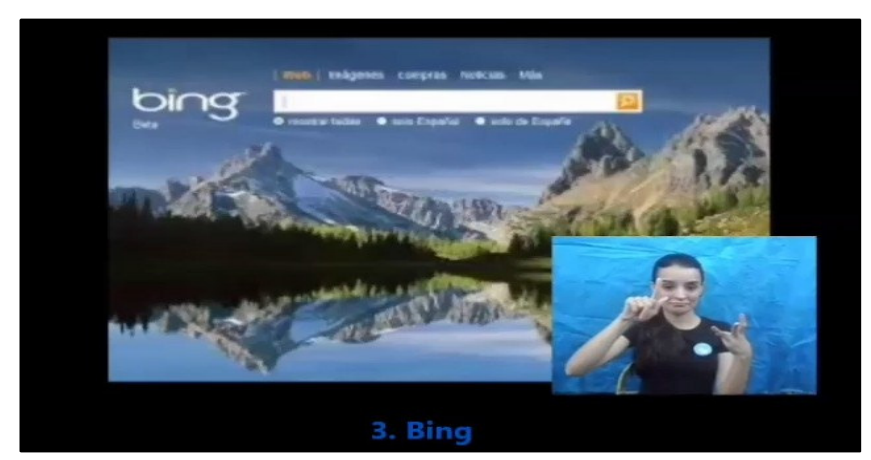

Fonte: Arquivos da pesquisa.

Essa figura apresenta algumas estratégias para dar destaque à informação desejada de sugerir à utilização de diferentes sites de busca, como, por exemplo, o Bing. Segundo Kress e van Leeuwen (2006), uma maneira de verificar a saliência é verificando o grau da atenção que um elemento chama para si, levando em consideração sua dimensão em relação aos outros elementos presentes na imagem. No caso do trecho retirado do vídeo tutorial, podemos perceber que a página do site de busca sugerido é apresentada em um

\footnotetext{
${ }^{5}$ O símbolo gráfico “Acessível em Libras” possui o foco na acessibilidade linguística através da Libras e "é utilizado para identificar o conteúdo originalmente produzido na língua ou com tradução/interpretação para Libras, a partir da Língua Portuguesa”. Informação disponível em:

<<https://www.ufmg.br/marca/libras/ >>. Acesso em: 01 jul. 2015.
} 
tamanho bem maior do que a janela da intérprete, fazendo com que a informação tenha mais destaque, uma vez que, para compreendê-la, não se faz necessário visualizar a interpretação em Libras, pelo fato de a imagem já ser bem objetiva e conseguir passar a mensagem desejada.

Outra estratégia que pode ser utilizada é a visualização dos valores tonais das cores, sua nitidez e sua definição. Nesse caso, a cor azul utilizada no fundo da janela da intérprete, nas letras da legenda, bem como na imagem do site, auxilia na percepção de que todas as informações apresentadas tratam do mesmo assunto. Ambas as estratégias utilizadas, destaque da imagem e coordenação das cores, facilitam a compreensão do aluno surdo em relação ao conteúdo apresentado no vídeo tutorial, visto que explora bastante a questão visual que é aguçada nas pessoas surdas.

$\mathrm{O}$ último aspecto analisado em relação à função composicional foi $o$ valor da informação. Este aspecto diz respeito à diagramação da página, ou seja, às posições assumidas pelos elementos que compõem os textos, que podem ser: a) esquerda e direita; (2) topo e base; e (3) centro e margem. Essas posições estão relacionadas aos pares denominados por Kress e van Leeuwen (2006) como: (1) dado e novo; (2) ideal e real; e (3) central e marginal. Em relação ao primeiro par de posições dos elementos nas páginas, analisamos o seguinte trecho do vídeo tutorial, apresentado na Figura 04, abaixo:

Figura 04 - Dado e novo no vídeo tutorial

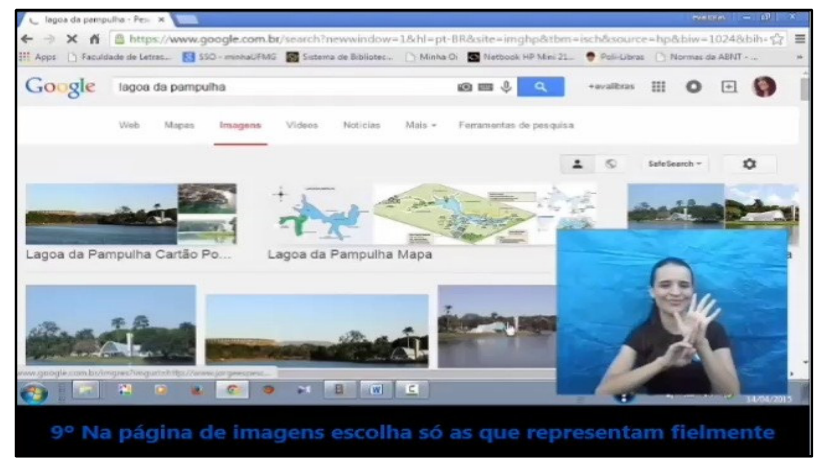

Fonte: Arquivos da pesquisa.

Nessa figura, o elemento dado (posicionado à esquerda) diz respeito às informações já conhecidas pelos alunos, ou seja, às imagens que podem ser encontradas no Google Imagens, enquanto o elemento novo (posicionado à direita) apresenta a sinalização da intérprete que orienta os alunos na forma correta de busca e escolha das imagens fornecidas por esse recurso da internet, ou seja, a informação que os alunos ainda desconhecem.

Em relação à posição ideal e real dos elementos na composição visual, analisamos a Figura 05, abaixo: 
Figura 05 - Ideal e Real no vídeo tutorial

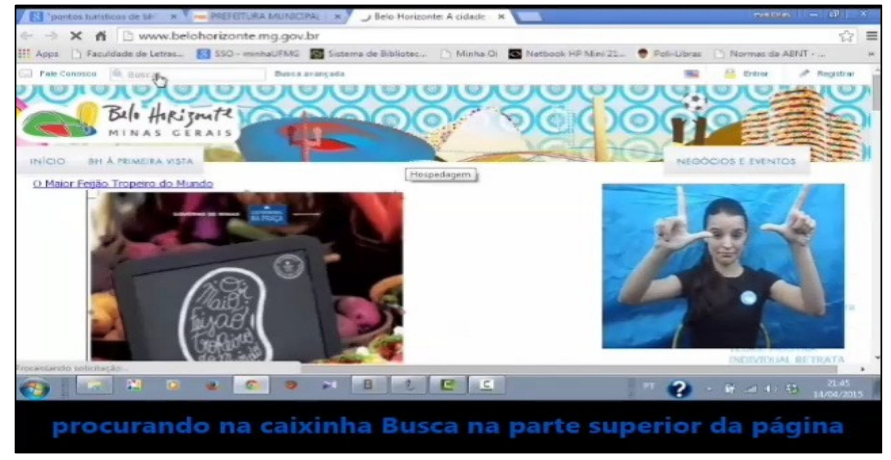

Fonte: Arquivos da pesquisa.

O elemento posicionado no topo da Figura 05 diz respeito ao menu superior do site da Prefeitura de Belo Horizonte, sendo que o elemento focalizado no vídeo tutorial é a caixinha "Buscar", na qual os alunos devem digitar palavras-chave para encontrarem o que desejam. Essa informação se coloca como ideal no contexto apresentado no vídeo tutorial pelo fato de representar uma ideia genérica, idealizada, ou seja, a noção de que os alunos poderão encontrar o que desejam saber apenas digitando o que procuram na caixinha. Já os elementos posicionados na base da tela do vídeo, representam o real, através da interpretação em Libras e da legenda em português, especificando o elemento superior e apresentando detalhes da informação.

Por fim, analisamos as posições central e marginal, a partir da Figura 06, abaixo:

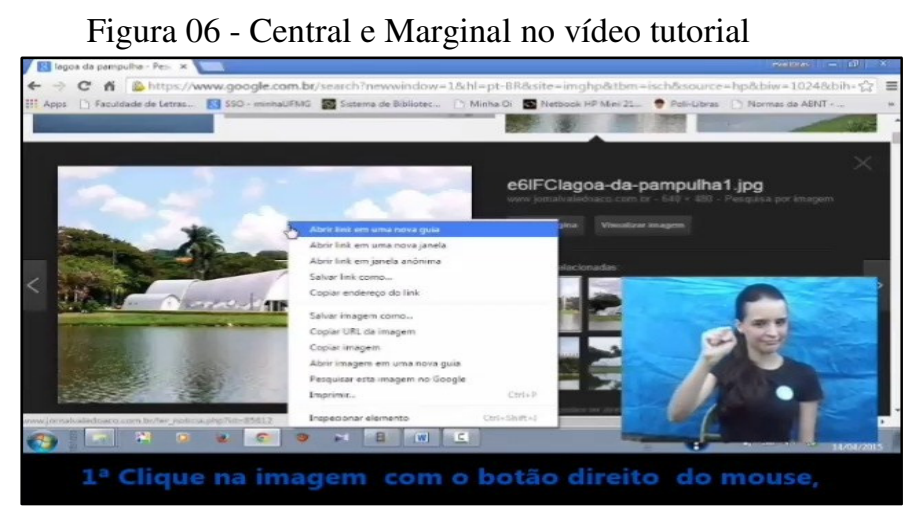

Fonte: Arquivos da pesquisa.

De acordo com Kress e van Leeuwen (2006), "para algo ser apresentado como centro significa que ele é apresentado como o núcleo da informação sobre a qual todos os outros elementos estão em algum sentido submissos" (KRESS; VAN LEEUWEN, 2006, p. 206, tradução nossa). Isso pode ser verificado na Figura 06, uma vez que o elemento central do trecho retirado do vídeo tutorial, que diz respeito à caixa de diálogo que aparece sobre a imagem no Google Imagens, ao ser clicada com o botão direito do mouse, se apresentam como a informação principal do contexto apresentado no vídeo. Enquanto isso, a imagem que aparece ao lado esquerdo e a interpretação em Libras ao lado direito, se apresentam como informações que complementam ou que especificam o que deve ser 
feito através da caixa de diálogo, ou seja, são dependentes das informações centrais da tela.

Por meio da análise dos aspectos do valor da informação, podemos perceber que as posições assumidas pelos elementos na página auxiliam na compreensão do aluno surdo em relação ao conteúdo veiculado pelo vídeo, uma vez que relacionam as informações entre si para formar um todo significativo, no qual cada parte tem sua importância e seu valor.

\section{2) Público a que se destina}

A segunda análise foi realizada a partir da categoria público a que se destina, proposta por Gomes (2008), para a avaliação de audiovisuais, levando em consideração não apenas trechos, mas o vídeo tutorial por completo. Segundo este autor, o professor não deve fazer uma avaliação dos meios de ensino apenas para selecioná-los, mas sim para adaptá-los tendo em vista seu público-alvo. No caso dos alunos surdos, essa avaliação deve ser ainda mais cuidadosa, uma vez que esses estudantes possuem especificidades educacionais que devem ser levadas em consideração no momento da seleção de materiais didáticos.

Em relação ao vídeo tutorial analisado, podemos perceber que o público é claramente definido e identificável, logo na abertura do vídeo, já que é possível visualizar o "Símbolo Acessível em Libras", a janela da intérprete de Libras e o uso da legenda. Além disso, é possível perceber que o público esperado não é somente de alunos surdos, uma vez que também há o recurso de áudio para que os alunos ouvintes possam acompanhar o que é apresentado no vídeo.

$\mathrm{O}$ vídeo tutorial analisado não requer que o aluno tenha um conhecimento prévio muito apurado do conteúdo veiculado, uma vez que dá orientações ao estudante para que ele possa realizar uma boa pesquisa online. Além disso, apresenta imagens do que está sendo falado, além do passo a passo que é realizado nos sites que deverão ser utilizados para a realização da tarefa proposta. Dessa forma, entendemos que a previsão de conhecimento prévio do público-alvo foi atendida.

Acreditamos que a proposta pedagógica, bem como a linguagem utilizada sejam adequadas ao público-alvo, levando em consideração que o vídeo tutorial busca utilizar recursos que facilitem a compreensão do aluno surdo em relação ao conteúdo veiculado, através do uso de imagens, da legenda e da interpretação em Libras.

Por fim, também consideramos que o formato do vídeo tutorial seja adequado ao público-alvo, já que, conforme explicitado anteriormente neste artigo, o uso de recursos tecnológicos no ensino de PL2 para surdos se configura como um instrumento metodológico eficaz, uma vez que auxilia na compreensão e na apreensão do conhecimento desses alunos (por meio da exploração de diferentes linguagens), além de propiciar o uso da LP escrita de maneira efetiva (RIBEIRO, 2012).

\section{5) CONSIDERAÇÕES FINAIS}


Por meio desta pesquisa, buscamos responder às seguintes questões: (1) como $o$ vídeo tutorial, por meio de seus recursos multimodais, pode contribuir ao ensino/aprendizagem do Português como Segunda Língua (PL2) para alunos surdos?; e (2) por que o vídeo tutorial produzido é adequado ao público a que se destina, ou seja, aos alunos surdos?. Para isso, analisamos um vídeo tutorial produzido para alunos surdos e ouvintes, a partir dos critérios propostos por Kress e van Leeuwen (2006), referentes à função composicional das imagens, e a categoria de público a que se destina, proposta por Gomes (2008).

Após a análise, confirmamos nossa hipótese de que o vídeo tutorial seja um recurso viável para o ensino de PL2 para alunos surdos, tanto em relação ao uso de recursos multimodais quanto em relação à sua adequação ao público-alvo. Isso se deve ao fato de que, os aspectos propostos por Kress e van Leeuwen (2006), auxiliam na compreensão do conteúdo veiculado, através da delimitação e da relação dos elementos da tela, por meio do enquadramento; do destaque das imagens e do uso das cores, através da saliência; e da hierarquia das posições ocupadas pelos recursos visuais, utilizando o valor da informação.

O vídeo tutorial analisado se mostra como um recurso educacional totalmente adequado aos alunos surdos, uma vez que seu público é claramente identificável; a previsão de conhecimentos prévios é atendida; sua proposta pedagógica e sua linguagem são adequadas, já que utiliza de imagens, da Libras e de legendas, a fim de facilitar a compreensão dos alunos; e seu formato também é apropriado, levando em consideração que os surdos estão cada vez mais inseridos no mundo digital e, através dos recursos tecnológicos, têm a oportunidade de utilizar a LP escrita de maneira efetiva.

Portanto, podemos concluir, que a exploração dos mais diversos modos de linguagem para formar um todo significativo, por parte do professor, se configura com um método facilitador do ensino/aprendizagem de PL2 para surdos, se comparado ao uso apenas da linguagem verbal. Dessa forma, se torna imprescindível que o professor que se encontra nesse contexto de ensino esteja preparado para utilizar materiais didáticos que atendam as especificidades de seus alunos e possam contribuir para o desenvolvimento do letramento digital, das competências comunicativas multimodais e do multiculturalismo, tão importantes para o conceito dos multiletramentos em nosso contexto atual de educação. No caso de desconhecimento da língua de sinais, o professor pode contar, por exemplo, com o auxílio do profissional intérprete de Libras para a criação de vídeos tutoriais como o que foi analisado, a fim de que seus alunos surdos tenham a mesma oportunidade de aprendizagem que os alunos ouvintes.

Por fim, é necessário enfatizar que, conforme afirma Gomes (2008), "a avaliação de um audiovisual didático é subjetiva” (GOMES, 2008, p. 490), dessa forma, a análise realizada neste artigo não se propõe a ser uma generalização e pode ser interpretada de outras maneiras, de acordo com a visão de cada leitor. Além disso, a análise através de trechos do vídeo tutorial (prints) pode não levar em consideração outros aspectos importantes, tais como a imagem em movimento. Porém, conforme explicitado na seção Metodologia, buscamos ser o mais explícitos possível em relação aos trechos 
selecionados, levando em consideração os objetivos propostos para este artigo. Dessa forma, outras análises poderão ser realizadas com outros objetivos, futuramente.

Através do estudo realizado buscamos também contribuir para as pesquisas relacionadas ao uso das NTICs no ensino de PL2 para alunos surdos, área que ainda é bastante incipiente.

\section{Referências}

COSCARELLI, Carla Viana; NOVAIS, Ana Elisa. Leitura: um processo cada vez mais complexo. Letras de Hoje, Porto Alegre, v. 45, n. 3, p. 35-42, jul./set. 2010. Disponível em: < http://revistaseletronicas.pucrs.br/ojs/index.php/fale/article/viewFile/8118/5807 >. Acesso em: 25 maio 2015.

DAL FORNO, Josiane. Discutindo as potencialidades dos vídeos tutoriais para a utilização em educação a distância. Revista Eletrônica em Gestão, Educação e Tecnologia Ambiental, Santa Maria, v. 12, n. 12, p. 2577-2583, jul. 2013. Disponível em: $<<$ http://cascavel.ufsm.br/revistas/ojs-

2.2.2/index.php/reget/article/viewFile/8689/pdf>>. Acesso em: 25 maio 2015.

FREIRE, Fernanda Maria Pereira. Surdez e Tecnologias de Informação e Comunicação. In: SILVA, Ivani Rodrigues; KAUCHAKJE, Samira; GESUELI, Zilda Maria. Cidadania, surdez e linguagem: desafios e realidade. São Paulo: Plexus, 2003.

GESSER, Audrei. Libras? Que língua é essa?: crenças e preconceitos em torno da Língua de Sinais e da realidade surda. São Paulo: Parábola, 2009.

GOMES, Luiz Fernando. Vídeos didáticos: uma proposta de critérios para análise.

Revista Brasileira de Estudos Pedagógicos, Brasília, v, 89, n. 223, p. 477-492,

set./dez. 2008. Disponível em:

<<http://rbep.inep.gov.br/index.php/rbep/article/view/688/666>>. Acesso em: 25 maio 2015 .

GROUP, The New London. A pedagogy of Multiliteracies: Designing Social Futures.

Harvard Educational Review, v. 66, n. 01, spring, 1996. Disponível em:

<<http://www.sfu.ca/ decaste/newlondon.htm>>. Acesso em: 07 set. 2016.

HEBERLE, Viviane. Multimodal Literacy for Teenage EFL Students. Cadernos de Letras, Rio de Janeiro, n. 27, p. 101-116, dez. 2010. Disponível em:<< http://www.letras.ufrj.br/anglo_germanicas/cadernos/numeros/122010/textos/cl3012201 00viviane.pdf $>>$. Acesso em: 25 maio 2015.

HEMAIS, Barbara. "Multimodalidade: enfoque para o professor de ensino médio". Janela de Ideias, 2010. Disponível em: <<http://www.letras.pucrio.br/unidades\&nucleos/JaneladeIdeias/biblioteca/B_Multimodalidade.pdf $>>$. Acesso em: 25 maio 2015. 
KALANTZIS, Mary; COPE, Bill. Literacies. Cambridge: Cambridge University Press, 2012.

KALANTZIS, Mary; COPE, Bill. Multiliteracies in Education. In: The Encyclopedia of Applied Linguistics, 2013. Disponível em: < http://onlinelibrary.wiley.com/doi/10.1002/9781405198431.wbeal0809/abstract;jsession id=BB5F491BD4BA079580668F60840ECFB4.f01t03 >>. Acesso em: 25 maio 2015.

KRESS, Gunther. Literacy in the New Media Age. London and New York: Routledge Taylor e Francis Group, 2003.

KRESS, Gunther; VAN LEEUWN, Theo. Multimodal Discourse: the modes and media of contemporary communication. Londres e Nova York: Routledge, 2001.

KRESS, Gunther; VAN LEEUWEN. Reading Images: the grammar of visual design. London and New York: Routledge, 2006.

LACERDA, Cristina Broglia Feitosa de; LODI, Ana Claudia Baliero. A inclusão escolar bilíngue de alunos surdos: princípios, breve histórico e perspectivas. In: (Org.). Uma escola duas línguas: letramento em língua portuguesa e língua de sinais nas etapas iniciais de escolarização. Porto Alegre: Mediação, 2009.

LAVILLE, Christian; DIONNE, Jean. A construção do saber: manual de metodologias da pesquisa em ciências humanas. Porto Alegre: Artmed, 1999.

MCCLEARY, Leland; VIOTTI, Evani. Transcrição de dados de uma língua sinalizada: um estudo piloto da transcrição na língua de sinais brasileira (LSB). In: CONGRESSO INTERNACIONAL DA ABRALIN, 04, 2005, Brasília. Anais... Brasília, 2005, p. 01$28 . \quad$ Disponível em: $<$ <https://www.academia.edu/456473/Transcri\%C3\%A7\%C3\%A3o_De_Dados_De_U ma_L\%C3\%ADngua_Sinalizada_Um_Estudo_Piloto_Da_Transcri\%C3\%A7\%C3\%A3 o_De_Narrativas_Na_L\%C3\%ADngua_De_Sinais_Brasileira_LSB_>>. Acesso em: 20 abr. 2015.

MEC (Ministério da Educação). O Tradutor e Intérprete de Língua Brasileira de Sinais e Língua Portuguesa. Secretaria de Estado de Educação Especial; Programa Nacional de Apoio à Educação de Surdos. Brasília: SEESP, 2004. Disponível em: $<<$ http://portal.mec.gov.br/seesp/arquivos/pdf/tradutorlibras.pdf $>$. Acesso em: 07 jun. 2015.

NASCIMENTO, Roseli Gonçalves do; BEZERRA, Fábio Alexandre Silva; HEBERLE, Viviane Maria. Multiletramentos: iniciação à análise de imagens. Linguagem \& Ensino, Pelotas, v. 14, n. 02, p. 529-552, jul./dez. 2011. Disponível em: $<<$ http://www.rle.ucpel.tche.br/index.php/rle/article/view/38>>. Acesso em: 25 maio 2015.

NOGUEIRA, Aryane Santos. Práticas de Letramento Multimodais em Ambiente 
Digital: uma Possibilidade para Repensar a Educação de Surdos. Intercâmbio, São Paulo, v. 28, p. 19-45, 2014. Disponível em: $<<$ http://revistas.pucsp.br/index.php/intercambio/article/view/19639/14513 >>. Acesso em: 31 maio 2015.

OLIVEIRA, Tâmara L. M. de; DIAS, Reinildes. Multimodalidade ontem e hoje nas homepages do Yahoo: trilhando uma análise diacrônica de textos multimodais. In: COSCARELLI, C. V.; KERSCH, D. F. Multiletramentos e multimodalidade: ações pedagógicas aplicadas à linguagem. Campinas: Pontes, s.d., p.79-107 (no prelo).

QUADROS, Ronice Müller de. Educação de surdos: a aquisição da linguagem. Porto Alegre: Artmed, 1997.

RIBEIRO, Maria Clara M. A. Língua Portuguesa como segunda língua para alunos surdos: propostas de atividades a partir de interfaces tecnológicas. Caderno Seminal Digital, ano 18, n. 18, v. 18, p. 91-104, jul./dez. 2012. Disponível em: << http://www.epublicacoes.uerj.br/index.php/cadernoseminal/article/view/11889>>. Acesso em: 25 maio 2015.

ROSE, Diana. Análise de imagens em movimento. IN: BAUER, Martin W.; GASKELL, George (Editores). Pesquisa qualitativa com texto, imagem e som: um manual prático. 6. ed. Petrópolis: Vozes, 2007. p. 343-364.

SANTOS, Paulo Ricardo dos; KLOSS, Sheila. A criança e a mídia: a importância do uso do vídeo em escolas de Joaçaba - SC. In: CONGRESSO DE CIÊNCIAS DA COMUNICAÇÃO NA REGIÃO SUL, 11, 2010, Novo Hamburgo. Anais... Novo Hamburgo: Intercom - Sociedade Brasileira de Estudos Interdisciplinares da Comunicação, 2010, p. 1-11. Disponível em: $<<$ http://www.intercom.org.br/papers/regionais/sul2010/resumos/R20-0957-1.pdf >>. Acesso em: 25 maio 2015.

SILVA, Giselli Mara da. Lendo e Sinalizando Textos: uma análise etnográfica das práticas de leitura em Português de uma turma de alunos surdos. 2010. Dissertação (Mestrado em Educação) - Faculdade de Educação, UFMG, Belo Horizonte. Disponível em: $<<$ http://www.bibliotecadigital.ufmg.br/dspace/bitstream/handle/1843/BUOS8CLNV9/diss erta_o_giselli_silva_2010.pdf?sequence=1 >>. Acesso em: 25 maio 2015.

ZACHARIAS, Valéria Ribeiro de Castro. Letramento Digital: desafios e possibilidades para o ensino. Belo Horizonte, 2016 (no prelo). 